Proceedings of XIX International Scientific Conference "New Technologies and Achievements in Metallurgy, Material Engineering, Production Engineering and Physics", Częstochowa, Poland, June 7-8, 2018

\title{
Impact of Annealing on Flattening of Magnetic Entropy Change versus Temperature Curves in Amorphous and Partially Crystallized $\mathrm{Fe}_{76} \mathrm{Mo}_{10} \mathrm{Cu}_{1} \mathrm{~B}_{13}$ Alloy
}

\author{
J. ŚwierCZeK ${ }^{a, *}$, A. KuPCZYK ${ }^{a}$ AND M. HASIAK ${ }^{b}$ \\ ${ }^{a}$ Institute of Physics, Częstochowa University of Technology, al. Armii Krajowej 19, 42-200 Częstochowa, Poland \\ ${ }^{b}$ Department of Mechanics and Materials Science, Wrocław University of Technology, \\ M. Smoluchowskiego 25, 50-370 Wrocław, Poland
}

\begin{abstract}
"Table-like" shape of the magnetic entropy change versus temperature, $\Delta S_{M}(T)$, curve in amorphous and partially crystallized $\mathrm{Fe}_{76} \mathrm{Mo}_{10} \mathrm{Cu}_{1} \mathrm{~B}_{13}$ alloy has been investigated. The single ribbons in the as-quenched state and after annealing within the amorphous state exhibit "caret-like" behavior of $\Delta S_{M}(T)$ near the Curie point, $T_{C}$, of the amorphous phase. Amorphous $\mathrm{Fe}_{76} \mathrm{Mo}_{10} \mathrm{Cu}_{1} \mathrm{~B}_{13}$ alloy shows the Curie point of $277 \mathrm{~K}$ in the as-quenched state. According to the invar effect $T_{C}$ decreases to $272 \mathrm{~K}$ and increases to $284 \mathrm{~K}$ after the annealing at $623 \mathrm{~K}$ and $673 \mathrm{~K}$ for $0.5 \mathrm{~h}$, respectively. Layered composite consisting of annealed ribbons shows almost flat mathematically modeled $\Delta S_{M}(T)$ curve in the temperature range from $262 \mathrm{~K}$ to $288 \mathrm{~K}$. The temperature span $\Delta T=26 \mathrm{~K}$ is rather modest but takes place exactly in the ambient temperature range. The modeled values of $\Delta S_{M}$ do not differ a lot from the maximum values of the single constituent. After the annealing at $823 \mathrm{~K}$ for $0.5 \mathrm{~h} \Delta S_{M}(T)$ curve for a single ribbon is flat in much wider temperature range than in the layered composite due to diversity of magnetic phases presented in the heat treated sample but $\Delta S_{M}$ values drastically decrease.
\end{abstract}

DOI: 10.12693/APhysPolA.135.212

PACS/topics: 75.50.Bb, 75.50.Kj, 75.60.Ej, 75.30.Sg

\section{Introduction}

Requirements made for magnetic refrigerant materials depend on the thermodynamic cycles they should undergo [1]. For the refrigerant appliances working near the room temperature the magnetic Ericsson cycle consisting of two isothermal and two isofield magnetization steps seems to be the most adequate. The Ericsson cycle is the most energetically efficient if the magnetic entropy change versus temperature $\left(\Delta S_{M}(T)\right)$ is almost constant in the temperature span $\Delta T=T_{\text {hot }}-T_{\text {cold }}$, where $T_{\text {hot }}$ and $T_{\text {cold }}$ correspond to the temperatures of hot and cold sinks, respectively [2]. Single magnetic phases usually do not exhibit such "table-like" behavior but a "caretlike" one with the peak value of $\Delta S_{M}(T)$ near the Curie point of the alloy, so for this reason the composite materials consisting of at least two magnetic phases are considered [1]. In the case of amorphous ferromagnets the composite is formed by two ribbons with different composition and consequently different Curie temperature. In this way the working temperature range is widened as compared to single phased refrigerant material [3]. The Curie temperature of the amorphous ferromagnet can be easily tuned not only by changes in chemical composition but by proper annealing within the amorphous state [4]. In this paper we present the thermomagnetic properties

*corresponding author; e-mail: swiercz@wip.pcz.pl of amorphous $\mathrm{Fe}_{76} \mathrm{Mo}_{10} \mathrm{Cu}_{1} \mathrm{~B}_{13}$ alloy in the as-quenched state and after annealing below and above the primary crystallization temperature. The properties of layered composite obtained from two amorphous ribbons with the same chemical composition but subjected to different heat treatments are discussed.

\section{Experimental procedure}

The amorphous ribbons, $10 \mathrm{~mm}$ wide and $20 \mu \mathrm{m}$ thick, with the nominal composition of $\mathrm{Fe}_{76} \mathrm{Mo}_{10} \mathrm{Cu}_{1} \mathrm{~B}_{13}$ were prepared by melt spinning method. The microstructure was studied by X-ray diffraction and the Mössbauer spectroscopy. A Brucker-AXS, type D8 Advanced X-ray diffractometer and a conventional constant acceleration spectrometer with a ${ }^{57} \mathrm{Co}(\mathrm{Rh})$ radioactive source were used. Transmission Mössbauer spectra were fitted using NORMOS package. The specific magnetization (magnetization per unit mass, $\sigma$ ) versus temperature in $50-$ $400 \mathrm{~K}$ range at the magnetizing field induction of $5 \mathrm{mT}$ by a VersaLab (Quantum Design) system was measured for disc samples. The isothermal magnetization curves $\sigma(B)$ (where $B$ is the magnetizing field induction) were obtained in 205-355 K temperature and $0-2 \mathrm{~T}$ of $B$ ranges. The amorphous transition metals based amorphous alloys exhibit the second order ferromagneticparamagnetic phase transition. Therefore, from the sets of isothermal magnetization curves $\sigma(B)$ the magnetic entropy change $\left(\Delta S_{M}(T)\right)$ can be calculated from the Maxwell thermodynamic equation [1] according to the procedure described in details in [5]. All measurements 
were performed and $\Delta S_{M}(T)$ were computed for samples in the as-quenched state and after the conventional annealing within the amorphous state and at temperature above the onset of primary crystallization. The annealing temperatures were determined from differential scanning calorimetry (DSC) curve recorded by means of a NETZSCH STA 449F1 setup at the heating rate of $10 \mathrm{~K} / \mathrm{min}$.

\section{Results and discussion}

According to the DSC curve the primary crystallization of the amorphous $\mathrm{Fe}_{78} \mathrm{Mo}_{10} \mathrm{Cu}_{1} \mathrm{~B}_{13}$ alloy starts at $703 \mathrm{~K}$ and the secondary at $937 \mathrm{~K}$, so the annealing temperatures $T_{a 1}=623 \mathrm{~K}$ and $T_{a 2}=673 \mathrm{~K}$ are far below the onset of crystallization, whereas $T_{a 3}=823 \mathrm{~K}$ is in the span of the primary crystallization. In Fig. 1 X-ray diffraction patterns for the as-quenched and annealed at $T_{a 1}, T_{a 2}$, and $T_{a 3} \mathrm{Fe}_{78} \mathrm{Mo}_{10} \mathrm{Cu}_{1} \mathrm{~B}_{13}$ amorphous ribbons are shown. The patterns for the as-quenched and annealed $T_{a 1}$ and $T_{a 2}$ for $0.5 \mathrm{~h}$ samples are typical of amorphous alloys with no traces of crystallization, although $\alpha$-Fe medium range ordered (MRO) regions $1-2 \mathrm{~nm}$ in size with small volume fraction (about $3 \%$ ) were revealed by transmission high-resolution electron microscopy and the Mössbauer spectroscopy [4]. After the annealing at $T_{a 3}$ the presence of peaks originating from the (110), (200), (211), and (220) planes in $\alpha$-Fe(Mo) crystalline grains are shown. By derivation of $\sigma(T)$ curves measured at $B=5 \mathrm{mT}$ the Curie points are derived and equal to $T_{C}=(277 \pm 1) \mathrm{K}, T_{C 1}=(272 \pm 1) \mathrm{K}$ and $T_{C 2}=(284 \pm 1) \mathrm{K}$ in the as-quenched state and after the annealing at $T_{a 1}$ and $T_{a 2}$, respectively. $T_{C}$ for the

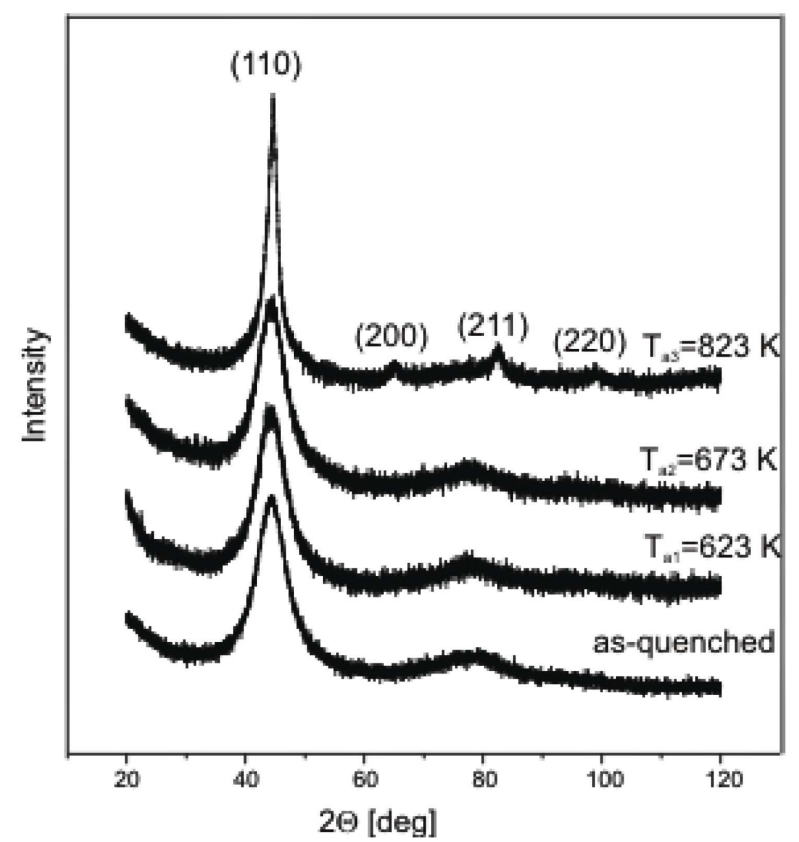

Fig. 1. X-ray diffraction patterns for the as-quenched and annealed at $T_{a 1}, T_{a 2}$, and $T_{a 3}$ for $0.5 \mathrm{~h}$ $\mathrm{Fe}_{76} \mathrm{Mo}_{10} \mathrm{Cu}_{1} \mathrm{~B}_{13}$ amorphous ribbons.

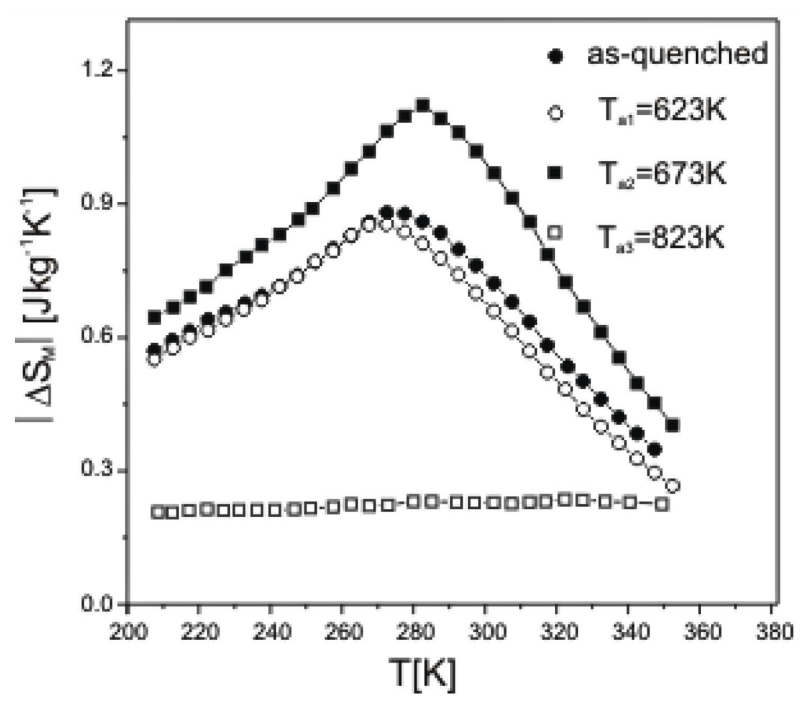

Fig. 2. Isothermal magnetic entropy change, $\Delta S_{M}$ versus temperature for the as-quenched and annealed at $T_{a 1}, T_{a 2}$, and $T_{a 3}$ for $0.5 \mathrm{~h} \mathrm{Fe}_{76} \mathrm{Mo}_{10} \mathrm{Cu}_{1} \mathrm{~B}_{13}$ amorphous ribbons.

as-quenched amorphous phase makes the material very interesting for magnetic refrigeration. The decrease of $T_{C}$ after annealing at $T_{a 1}$ may be attributed to the annealing out of free volumes. Consequently, the average distance between $\mathrm{Fe}$ atoms and the exchange interaction between them decrease resulting in lowering of $T_{C}$. During annealing at higher temperature $\left(T_{a 2}\right)$ two mechanisms play the role - the mentioned above annealing out of free volumes and diffusion of atoms which may lead to strengthening of the exchange interaction between magnetic atoms and the enhancement of the Curie temperature is observed. Therefore, the Curie point of the amorphous phase due to invar effect can be easily tuned by proper conventional annealing. In Fig. $2 \Delta S_{M}$ versus temperature for the as-quenched and annealed samples is depicted. In the as-quenched state and after the annealing within the amorphous state $\left(T_{a 1}\right.$ and $\left.T_{a 2}\right) \Delta S_{M}(T)$ exhibits the "caret-like" behavior with the peak value close to the Curie temperature of the amorphous phase. After annealing at $T_{a 3}$, as revealed by transmission Mössbauer spectroscopy [6], the amorphous paramagnetic and ferromagnetic phases, interface zone, and crystalline $\alpha$ Fe grains are presented in the samples at room temperature. The diversity of the magnetic phases with different Curie points causes the distinct flattening of $\Delta S_{M}(T)$ curve and drastic decrease of $\Delta \mathrm{S}_{M}$ value (Fig. 2). If the composite from two adherent ribbons subjected to the heat treatments at $T_{a 1}$ and $T_{a 2}$ is considered, neglecting magnetic dipolar interactions between ribbons $\Delta S_{M}$ of the composite can be mathematically modeled by:

$$
\Delta S_{M}(T)=\alpha \Delta S_{M 1}(T)+(1-\alpha) \Delta S_{M 2}(T),
$$

where $\Delta S_{M 1}(T)$ and $\Delta S_{M 2}(T)$ are magnetic entropy change of composite constituents, $\alpha$ is the mass fraction of the first constituent. Such composite has the temperature span of the Curie point equal to $12 \mathrm{~K}$. 


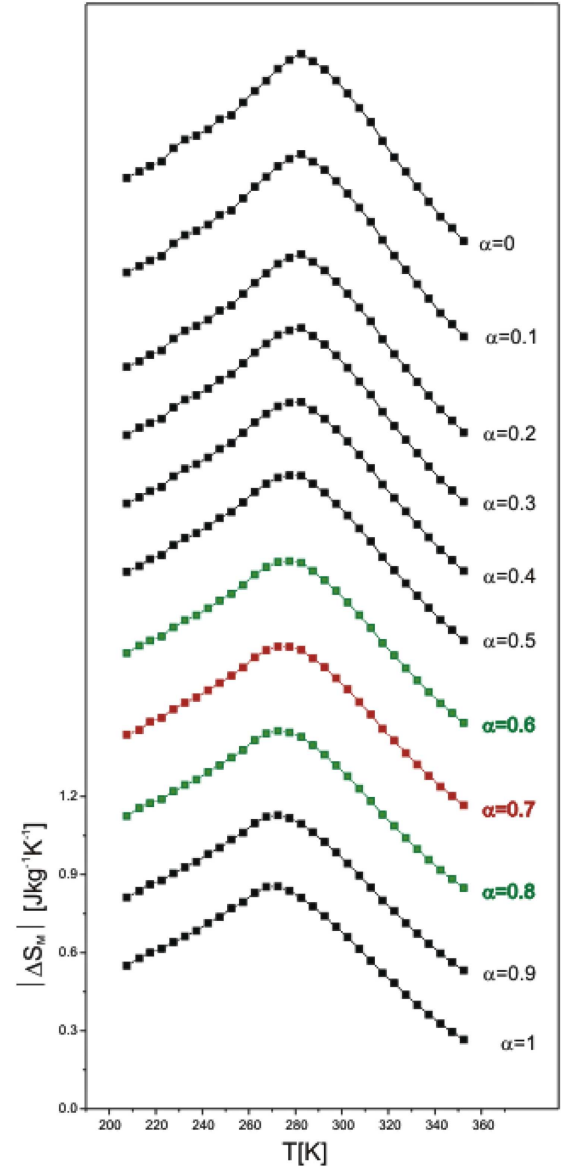

Fig. 3. Mathematically modeled magnetic entropy change as a function of temperature for the layered composite consisted of two $\mathrm{Fe}_{76} \mathrm{Mo}_{10} \mathrm{Cu}_{1} \mathrm{~B}_{13}$ amorphous ribbons subjected to the annealing within the amorphous state with different mass fraction of the constituents $(\alpha)$. The scale of the vertical line refers only to the ribbon annealed at $T_{a 1}=623 \mathrm{~K}$ for $0.5 \mathrm{~h}(\alpha=1)$.

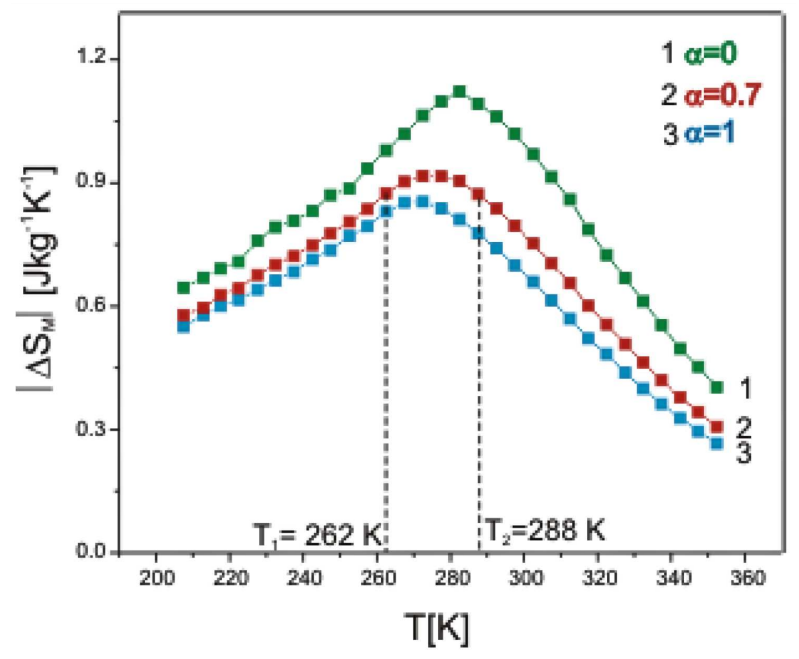

Fig. 4. Temperature dependence of the mathematically modeled magnetic entropy change for the composite $(\alpha=0.7)$ and measured single components $(\alpha=1$ and $\alpha=0)$.
$\Delta S_{M}(T)$ curves for the composite for different values of $\alpha$ are presented in Fig. 3. The most flattened maximum is obtained for $\alpha=0.7$ but the shape of maxima for $\alpha=0.6$ and $\alpha=0.8$ does not differ a lot. For the comparison in Fig. $4 \Delta S_{M}(T)$ for the single ribbons of the $\mathrm{Fe}_{76} \mathrm{Mo}_{10} \mathrm{Cu}_{1} \mathrm{~B}_{13}$ alloy subjected to the heat treatment at $T_{a 1}$ and $T_{a 2}(\alpha=1$ and $\alpha=0)$ and for the composite with the mass fraction $\alpha=0.7$ are shown. The almost flat maximum for the composite is obtained in the temperature range from $262 \mathrm{~K}$ to $288 \mathrm{~K}(\Delta T=26 \mathrm{~K})$ and is higher than the difference in the Curie points of the constituents. The temperature span is rather modest but is very interesting because is obtained by annealing the amorphous ribbons with the same chemical composition within the amorphous state and lies in the room temperature range. Additionally, the maximum value of $\Delta S_{M}$ of the composite does not differ a lot from these of the constituents contrary to the single ribbon heat treated in the primary crystallization range for which the distinct increase of flattening temperature span is accompanied by drastic decrease of $\Delta S_{M}$ value (Fig. 2).

\section{Conclusions}

The values of the magnetic entropy change and the temperature span $\Delta T=26 \mathrm{~K}$ of almost flat $\Delta S_{M}(T)$ curve for the composite formed by two adherent ribbons annealed at $T_{a 1}$ and $T_{a 2}$ for $0.5 \mathrm{~h}$ are rather modest. Taking into account the prices of raw elements, possibility to tune the Curie point not only by changes in chemical composition but by the proper conventional annealing the ribbons with the same composition, as well and considering the fact that $\Delta T$ is in the vicinity of room temperature, the investigated material may be interesting for magnetic refrigeration technology.

\section{References}

[1] V. Franco, J.S. Blázquez, J.J. Ipus, J.Y. Law, L.M. Moreno-Ramírez, A. Conde, Prog. Mater. Sci 93, 112 (2018) and reference therein.

[2] B.F. Yu, Q. Gao, B. Zhang, X.Z. Meng, Z. Chen, Int. J. Refrig. 26, 622 (2003).

[3] P. Álvarez, P. Gorria, J.L. Sánchez Llamazarez, J.A. Blanco, J. Alloys Comp. 568, 98 (2013).

[4] J. Świerczek, M. Hasiak, IEEE Trans. Magn. 50, 2003504 (2014).

[5] J. Świerczek, J. Magn. Magn. Mater. 322, 2696 (2010).

[6] J.Świerczek, J. Alloys Comp. 615, 255 (2014). 